\title{
Abortion in Captive Gray Brocket Deer (Mazama gouazoubira) Associated with Colloid Goiter, Hemonchosis and Necrotizing Rumenitis
}

\author{
Leonardo Lima Gorza ${ }^{1}$, Ellen Cristina de Oliveiraa ${ }^{1}$, Carlos Eduardo Bastos Lopes ${ }^{1}$, \\ Eduardo Lazaro de Faria da Silva², Emy Hiura ${ }^{3}$, Mayra Cunha Flecher ${ }^{3}$, \\ Tayse Domingues de Souza ${ }^{3}$ \& Fábio Ribeiro Braga ${ }_{\odot}^{3}$
}

\begin{abstract}
Background: The gray brocket deer (Mazama gouazoubira) is a specie that shows great adaptability in different habitats and it is the most abundant deer specie in South America. The present work describes for the first time a case of abortion followed by death associated with colloid goiter, massive hemonchosis and necrotizing rumenitis in a captive female gray brocket deer.

Case: A 4-year-old female gray brocket deer (M. gouazoubira) raised in captivity had a history of abortion during the last third of gestation. The animal was kept in an enclosure together with 3 other gray brockets deers, being 1 male of the same age and 2 juvenile brocket deer of approximately 1 and 2 years old. The animals were fed with concentrated used as cattle feed and dewormed annually with $1 \%$ Ivermectin. The animals' enclosure had vegetation cover formed by grasses and soil. The animals appeared healthy with no behavioral changes. The day after the stillbirth, the mother was found dead in the enclosure and sent to the animal pathology sector of the University of Vila Velha (UVV), Brazil. Necropsy revealed that thyroid lobules were highly increased in volume and histopathological findings were compatible with colloid goiter. A large number of nematodes were found in the abomasal content, totalizing 11,626 helminths, which were morphologically characterized as Haemonchus contortus. Grossly, the serous and ruminal mucosa exhibited an extensively reddish focal area with irregular contour, surface ulceration and a firm consistency. Microscopically, a severe necrotizing rumenitis was diagnosed. The liver showed pale multifocal areas on the subcapsular surface, friable to the touch which deepened when cut. Histopathological analysis revealed an accentuated multifocal panlobular coagulative necrosis, characterizing an acute liver necrosis.

Discussion: Iodine is a mineral of great importance for thyroid hormones synthesis and your requirements are higher during pregnancy and lactation. Diets deficient in iodine causes a reduction in the basal activity of the hormones triiodothyronine (T3) and thyroxine (T4) and over-stimulation of the thyroid by thyroid stimulating hormone (TSH), resulting in goiter. In the present case, it is possible that the shortage of iodine in diet caused a goiter and, as a consequence, triggered the abortion. Haemonchus contortus is a pathogenic nematode of small ruminants, leading to decreased productivity and death in some cases as a result of anemia and hypoxia. The contact between domestic and wild animals, resulting in the emergence of infectious diseases and the spread of pathogens among species. In the present case, manual counting accounted for 11,626 $H$. contortus larvae, characterizing a massive infection and justifying the condition of severe anemia. The high parasitic load shown in this case points out this parasite's importance related to this species in captivity. In general, inflammatory lesions in the rumen are results of excessive intake of fermentable carbohydrates, which leads to a considerable decrease in ruminal $\mathrm{pH}$ and leads to a high proliferation of lactic acid bacteria. This lesion has been previously reported in cervids. This case of comorbidities demonstrates that failures in nutritional and health handling, may cause simultaneous multiple diseases leading to death. Preventive measures for helminth parasite control and a proper feeding management with an adequate diet must be provided in order to preserve the species in captivity.
\end{abstract}

Keywords: colloid goiter, abortion, cervids, Haemonchus contortus.

DOI: $10.22456 / 1679-9216.114003$

Received: 17 May 2021

Accepted: 18 August 2021

Published: 25 October 2021

${ }^{1}$ Department of Veterinary Medicine and Surgery, University of Minas Gerais (UFMG), Belo Horizonte, MG, Brazil. ${ }^{2}$ Veterinarian at the Hospital Silvestres, Vila Velha, ES, Brazil. ${ }^{3}$ Department of Veterinary Medicine, University of Vila Velha (UVV), Vila Velha. CORRESPONDENCE: L.L.Gorza [leonardo_limagorza@ @otmail.com]. Department of Veterinary Medicine and Surgery, Veterinary School - UFMG. Av. Presidente Antônio Carlos n. 6627. CEP 31270-901 Belo Horizonte, MG, Brazil. 


\section{INTRODUCTION}

Cervids are ruminant ungulates of the order Artiodactyla, distributed worldwide in multiple countries and biomes [2]. Feeding is one of the most important aspects in the management of these animals in captivity, and basically consists in concentrate, such as cattle food, and roughage [2]. Diets containing low levels of iodine highly predisposes to development of goiter, clinically characterized by hypothyroidism and abortion in some cases [8]. The gray brocket (Mazama gouzoubira) is the most abundant deer species in South America, and as far as we could notice, there is no previous report of nutritional goiter followed by abortion in this species [6]. The natural ability to adapt to different environmental conditions allows contact between the gray brocket deer and some domestic ruminants, which may result in the spread of pathogens among species, such as gastrointestinal parasites [3,9].

Haemonchus contortus is a gastrointestinal nematode frequently diagnosed in small domestic ruminants [12]. In the gray brocket, this parasite has been described in studies concerning the description of the helminth fauna [3], and indicators of parasitic infection [4]. Although haemonchosis has been additionally reported in free-living gray brocket deer $[3,4]$, its importance in captivity deer has not yet been documented.

Ruminal acidosis due to carbohydrate overload is a major problem in livestock [13], but its occurrence is still poorly described in wild ruminants [6]. Therefore, the aim of this study was to report a case of abortion associated with colloid goiter, massive hemonchosis, and necrotizing rumenitis in a captive gray brocket deer.

\section{CASE}

A 4-year-old captive female gray brocket deer (Mazama gouazoubira) presented abortion during the last third of gestation. The animal was being kept in captive, with no previous history of any clinical comorbidities. A day after abortion, the mother was found dead in the enclosure and was referred to necropsy at University of Vila Velha, Brazil. The female was being kept in an enclosure with 3 other gray brocket deer, 1 male of same age, and 2 younger brocket deer ( 1 and 2 years old, respectively).

The animals were been fed every $24 \mathrm{~h}$ with concentrate used in cattle feeding, and were annually dewormed with Ivermectin ${ }^{1}$. Vegetal cover inside the enclosure was composed mostly of Brachiaria spp. On post mortem examination blood was hydremic and mucous membranes were intensely pale. The thyroid lobules were bilaterally and diffusely enlarged, and firmly consistent (Figure 1A). Within the uterine body there was a moderate amount of cloudy and mucous content. In the gross evaluation of the forestomaches, a focally extensive reddish area of ulceration with irregular and firm borders was observed in the ruminal mucosa (Figure 1B). In the abomasal content there was a large number of white and red striped and cylindricalshaped helminths, with average corporal length of $30 \mathrm{~mm}$ (Figure 1C). The large intestine loops were diffusely filled with a dark red fluid (digested blood). A few areas of serosal hemorrhages were additionally seen in the centripetal gyri of the colon. In the subcapsular hepatic surface, there were multifocal pale, deep, and friable areas (Figure 1D). During necropsy, the abomasal content was sent for laboratory analysis in order to perform morphological characterization of the helminths and the parasitic load. Based on morphological features, parasites were characterized as Haemonchus contortus [12]. A total of 11,626 helminths were accounted for analyzed abomasal content.

Samples of thyroid, forestomaches, abomasum, small and large intestines, liver, uterus, trachea, lung, heart, lymph nodes, spleen and kidney were fixed at $10 \%$ buffered formalin, and submitted for routine histological processing. Microscopically, thyroid follicles were lined by a single layer of flattened cells, and markedly dilated and filled by a homogeneous, dense and eosinophilic material (colloid) [Figure 2], which characterizes colloid goiter. In the ruminal mucosa, there was an intense necrotizing rumenitis.

Histopathological analysis of the liver revealed a marked multifocal panlobular coagulative necrosis, with severe and diffuse vacuolar glycogenic degeneration. Such findings were characteristic of acute liver necrosis.

Additional findings included acute moderate catarrhal metritis and mild neutrophilic interstitial pneumonia.

\section{DISCUSSION}

Iodine is an essential mineral for human and animal health, since it is essential during the synthesis of thyroid hormones. Deficiency of iodine in the diet causes a decrease in the basal activity of the hormones triiodothyronine (T3) and thyroxine (T4), 


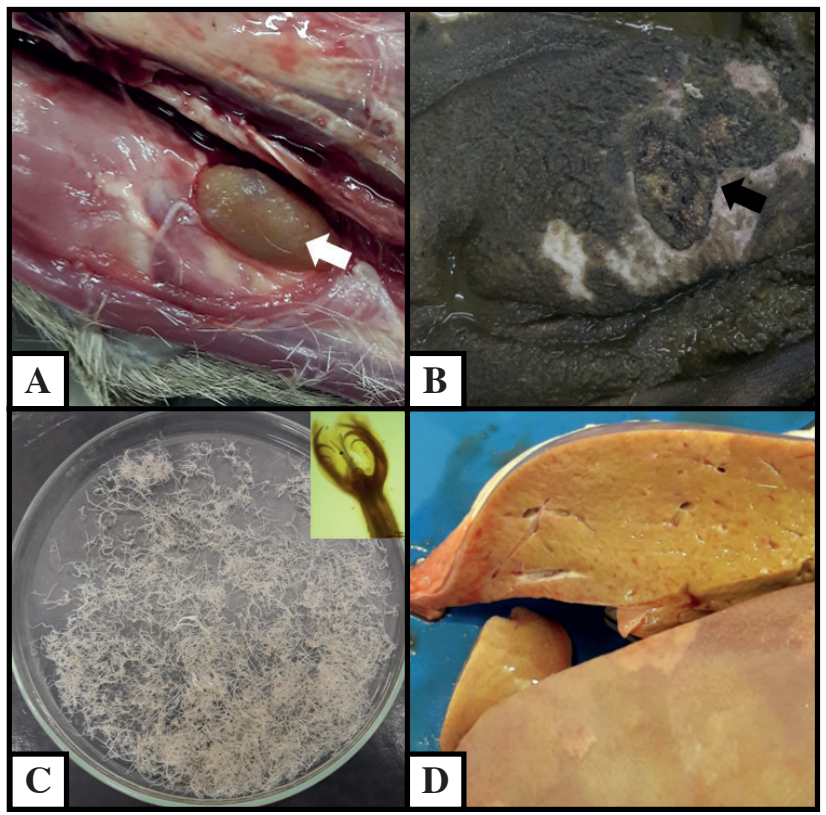

Figure 1. Main gross findings of female gray brocket deer during necropsy. A- Cervical region showing diffusely enlarged of the right thyroid gland (white arrow). B- Rumen. Ruminal mucosa with a focally extensive dark area of ulceration circumscribed by firm borders (black arrow). C- Petri dish filled with Haemonchus contortus from abomasal content. In the annex it is possible show the direct magnification of Haemonchus contortus, posterior view showing asymmetrical " $\mathrm{v}$ " shape dorsal ray $(*)[\mathrm{Bar}=50$ $\mu \mathrm{m}]$. D- Liver, capsular and cut surface with multifocal pale and friable areas, characteristic of acute liver necrosis.

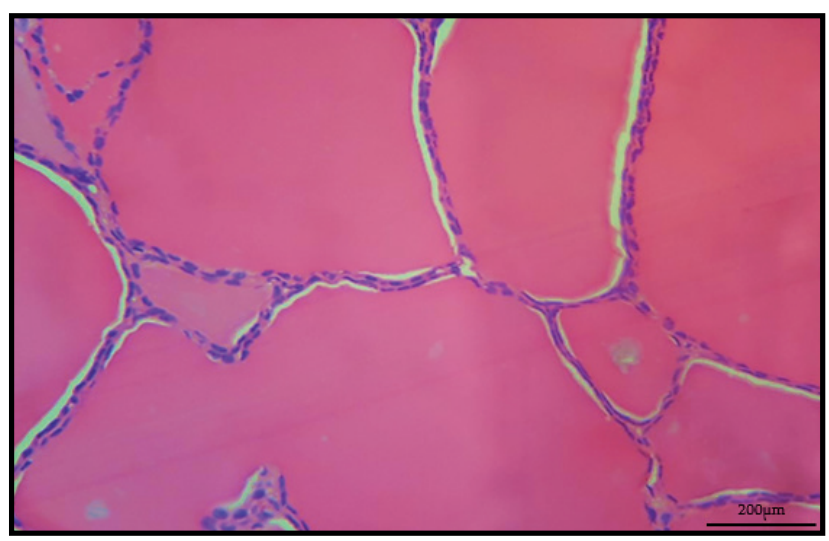

Figure 2. Thyroid gland. Distended follicles lined by a single layer of flattened cells, and filled by a homogeneous, dense and eosinophilic material (colloid) [HE; Bar $=200 \mu \mathrm{m}]$.

and over-stimulation of the thyroid by the thyroid stimulating hormone (TSH), resulting in goiter [8]. Iodine requirements are higher during pregnancy and lactation. In humans, inadequate mineral intake during pregnancy may lead to goiter, neonatal hypothyroidism, intellectual disabilities, and abortion [7]. In the present case, no clinical manifestations of hypothyroidism were previously noted. So, it was not affordable to perform serological dosages of any thyroid hormones by the time of the postmortem exam.
A retrospective study carried out in the state of Mato Grosso, Brazil, analyzed some epidemiological and anatomopathological findings of three outbreaks of goiter in cattle, which lived in properties with history of abortion and birth of weak and underdeveloped animals, highlighting the importance of the disease in livestock [5]. Thus, it is possible that the shortage of iodine in diet has triggered goiter, which resulted in abortion in the present case. According with a previously study [6], the most frequent causes of death in gray brockets were traumatic damage (36.6\%), respiratory (15.2\%), and capture myopathy, with no report of goiter in this study.

During the last few years, the constant loss of habitats has approached domestic and wild animals, resulting in the emergence of several infectious diseases [11] by the spreading of pathogens among species $[3,4,9]$. A study performed in the Brazilian Pantanal with 10 gray brockets suggested that the helminth fauna of these animals may have been derived from domestic cattle introduced in that area [3]. It has been additionally described that $H$. contortus is frequently associated with infections in this cervid species by comparing both the number of infected animals and the parasite load, suggesting that the host may be fairly adapted. Due to its wide distribution in South America, cervids are often seen around areas occupied by agriculture and domestic animals [3], which may act as important sources of infection for cervids.

Parasitism by $H$. contortus represents an important issue in small ruminants breeding, leading to production drops and death in some cases $[10,12]$. Anemia and hypoxia occur as a result of the bloodsucking habits of the parasite, and are the main reasons for death. The parasitic load is an important factor in the severity of haemonchosis, once a previous study reported that each adult helminth ingests about $0.05 \mathrm{~mL}$ of blood per day [1]. In the present report, manual counting totalized 11,626 larvae, characterizing a massive infection of $H$. contortus, and justifying the condition of severe anemia. A few strategies have been developed in order to reduce the animal losses related to the parasitism. An experimental study described a reduction of $H$. contortus larvae (L3) in sheep feces through the use of conidia of the nematophagous fungi Duddingtonia flagrans and Monacrosporium thaumasium [10], which can be an alternative control method for hemoncosis in captive wild ruminants. 
The high parasitic counting described here enhances the importance of this host-parasite relationship in captivity situations.

Inflammatory lesions in the rumen are frequently reported in most domestic ruminants, and in free-living gray brockets [6]. Basically, these chemical injuries occur as result of excessive intake of highly fermentable carbohydrates, which leads to a sudden decrease in ruminal $\mathrm{pH}$, leading to a high proliferation of lactic acid producing bacteria [13]. The ruminal lesions found in the present case were consistent to those reported in cases of rumenitis in the literature [13]. The feeding management of the reported deer was based on measures of concentrate for cattle, which was probably the cause of the ruminal lesion. Although it was not possible to identify the bacterial agent involved in the present case, the bacterial agents frequently involved in cases of ruminal acidosis followed by necrotizing rumenitis used to be from the own ruminal microbiota, such as Fusobacterium necrophorum and Clostridium spp. [13]. Moreover, liver damage may have resulted from septic thromboembolism, secondary to the primary ruminal lesion.
In conclusion, it is reported a case of abortion associated with colloid goiter, massive haemonchosis and necrotizing rumenitis in a captive deer $(M$. gouazoubira). This is the first report of colloid goiter in this species. Moreover, successive management failures may cause concomitant diseases and lead to death in a short term. Preventive actions to control parasites and provide adequate diets during pregnancy and postpartum must be adopted to preserve the species in captive.

\section{MANUFACTURER}

${ }^{1}$ Merial Saúde Animal - Boehringer Ingelheim. Lyon, France.

Acknowledgements. The authors thank to CNPq (Conselho Nacional de Desenvolvimento Científico e Tecnológico), CAPES (Coordenação de Aperfeiçoamento de Pessoal de Nível Superior) and FAPES (Fundação de Apoio á Pesquisa do Espírito Santo) Edital no 18/20 Programa de Desenvolvimento da Pós-Graduação (PDPG -Parceria Estratégica nos Estados, for funding this study. They are also very grateful to students Marina Gusman and Bianca Spelta for all the assistance in the case.

Declaration of interest. The author declare that they have no conflicts of interest. The authors are responsible for the manuscript content.

\section{REFERENCES}

1 Clark C.H., Kiesel G.K. \& Goby C.H. 1962. Measurements of blood loss caused by Haemonchus contortus infection in 177 sheep. American Journal of Veterinary Research. 23: 977-980.

2 Duarte J.M.B. 2014. Artiodactyla-Cervidae (Veados e Cervos). In: Cubas Z.S., Silva J.C.R. \& Catão-Dias J.L. (Eds). Tratado de Animais Selvagens. 2.ed. São Paulo: Roca, pp.2274-2301.

3 Lux-Hoppe E.G., Tebaldi J.H. \& Nascimento A.A. 2010. Helminthological screening of free-ranging grey brocket deer Mazama gouazoubira Fischer, 1817 (Cervidae: Odocoileini) from Brazilian Pantanal wetlands, with considerations on Pygarginema verrucosa (Molin, 1860) Kadenatzii, 1948 (Spirocercidae: Ascaropsinae). Brazilian Journal of Biology. 70: 417-423.

4 Marques S.M.T., Quadros R.M., Mazzolli M. \& Jesus J.R. 2007. Parasitos gastrintestinais em veados (Mazama gouazoubira) de áreas nativas no planalto de Santa Catarina, Brasil. Veterinária em Foco. 5: 1-8.

5 Martins K.P.F., Fonseca T.R.S., Silva E.S., Munhoz T.C.P., Dias G.H.S., Galiza G.J.N., Oliveira L.G.S. \& Bobaid F.M. 2018. Bócio em bovinos. Pesquisa Veterinária Brasileira. 38: 1030- 1037.

6 Navas-Suárez P.E., Delgado-Diaz J., Matushima E.R., Favero C.M., Sarmiento A.M.S., Sacristán C., Ewbank A.C., Joppert A.M., Duarte J.M.B., Santos-Cirqueira C.S., Cogliati B., Mesquita L., Maiorka P.C. \& Catão-Dias J.L. 2018. A retrospective pathology study of two Neotropical deer species (1995-2015), Brazil: Marsh deer (Blastocerus dichotomus) and brown brocket deer (Mazama gouazoubira). PloS One. 13: 1-26.

7 Pearce E.N. 2012. Effects of iodine deficiency in pregnancy. Journal of Trace Elements in Medicine and Biology. 26: 131-133.

8 Rosol T.J. \& Gröne A. 2016. Endocrine Glands. In: Maxie G.M. (Ed). Pathology of Domestic Animals. San Diego: Saunders, pp.310-336.

9 Shen D.D., Wang J.F., Zhang D.Y., Peng Z.W., Yang T.Y., Wang Z.D., Bowman D.D., Hou Z.J. \& Liu Z.S. 2017. Genetic diversity of Haemonchus contortus isolated from sympatric wild blue sheep (Pseudois nayaur) and sheep in Helan Mountains, China. Parasites \& Vectors. 10: 1-10. 
L.L. Gorza, E.C. Oliveira, C.E.B. Lopes, et al. 2021. Abortion in Captive Gray Brocket Deer (Mazama gouazoubira) Associated with Colloid Goiter, Hemonchosis and Necrotizing Rumenitis. Acta Scientiae Veterinariae. 49(Suppl 1): 693.

10 Silva A.R., Araújo J.V., Braga FR., Alves C.D. \& Frassy L.N. 2011. Activity in vitro of fungal conidia of Duddingtonia flagrans and Monacrosporium thaumasium on Haemonchus contortus infective larvae. Journal of Helminthology. 85: 138-141.

11 Smith K.F., Acevedo-Whitehouse K. \& Pedersen A.B. 2009. The role of infectious diseases in biological conservation. Animal Conservation. 12: 1-12.

12 Tak I.R., Dar S.A., Dar J.S., Ganai B.A., Chisthi M.Z. \& Ahmad F. 2014. A Brief Study of Morphology of Haemonchus contortus and its Hematophagus Behaviour. Global Veterinaria. 13: 960-965.

13 Uzal F.A., Plattner B.L. \& Hostetter J.M. 2016. Alimentary System. In: Maxie G.M (Ed). Pathology of Domestic Animals. San Diego: Saunders, pp.35-60. 